\title{
Registro visual do lobo-guará, Chrysocyon brachyurus (Illiger, 1815) (Mammalia: Carnivora: Canidae) na Floresta Nacional de Três Barras, SC
}

\author{
Sérgio Bazilio ${ }^{1 *}$ \\ Zelinda Schemczssen ${ }^{1}$ \\ Anésio da Cunha Marques \\ ${ }^{1}$ Faculdade Estadual de Filosofia, Ciências e Letras de União da Vitória \\ Curso de Ciências Biológicas \\ Praça Cel. Amazonas, s/n, CEP 84600-000, União da Vitória, PR - Brasil \\ ${ }^{2}$ IBAMA - Flona de Três Barras, BR-280, Km 213 \\ Caixa Postal 204, CEP 88490-000, Barra Grande - SC, Brasil \\ *Autor para correspondência \\ serbazilio@yahoo.com.br
}

Submetido em 01/02/2009

Aceito para publicação em 25/08/2009

\section{Resumo}

O lobo-guará é o maior representante da família dos canídeos na América do Sul, vive em ambientes abertos, como campo e cerrado, também encontrado próximo a brejos e matas ao longo de cursos de água. Esta nota relata a visualização direta de um exemplar na Floresta Nacional (Flona) do Ibama em Três Barras, SC (lat. 26¹0'15”S; long. 50¹0'15”'W e elev. 750m) que é caracterizada por remanescentes de Floresta Ombrofila Mista e apresenta grandes áreas com reflorestamento de Pinus e Araucária com mais de 50 anos. Possui uma área de $4.458,5$ ha, isotermas de 20 a $22^{\circ} \mathrm{C}$ em janeiro e de 12 a $14^{\circ} \mathrm{C}$ em julho, com média de umidade relativa do ar anual de $85 \%$ e precipitações entre 1.200 e $1.400 \mathrm{~mm}$ por ano. Um exemplar adulto foi visualizado, pela manhã, várias vezes por funcionários do Ibama no final de junho de 2008 entre as coordenadas (lat. 26 $6^{\circ} 12^{\prime} 56^{\prime \prime} \mathrm{S}$;

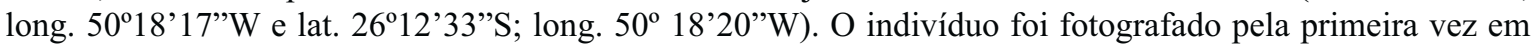
três de julho às $7 \mathrm{~h} 30 \mathrm{~min}$ e a segunda vez no dia 19 do mesmo mês às $7 \mathrm{~h} 48 \mathrm{~min}$ no mesmo local, na estrada de acesso à sede da Flona.

Unitermos: Chrysocyon brachyurus, Flona, lobo-guará, visualização

\section{Abstract}

View registration of lobo-guará (Carnivore, Canidae, Chrysocyon brachyurus) in the National Forest of Três Barras, SC. The lobo-guará is the major representative of the family of Canidae in South America. It lives in an open environment, such as fields and scrub. It is also found in nearby swamps and woods along the courses of water. This note narrates the viewing of an adult specimen of the lobo-guará in the National Forest (Flona) of Ibama in Três Barras, SC (lat. 26¹0'15"S; long. 50'10'15”W and elev. 750m) that is characterized by remnants of Mixed Ombrofila Forest and presents huge areas with reforestation of Pinus sp. and Araucaria angustifolia of over 50 years of age. The Flona has an area of 4,458.5ha, with isotherms of 20 to $22^{\circ} \mathrm{C}$ in January 
and 12 to $14^{\circ} \mathrm{C}$ in July. The average annual relative humidity of the air is $85 \%$ and it precipitates between 1,200 and $1,400 \mathrm{~mm}$ each year. The animal was seen many times in the morning by employees of Ibama at the end of

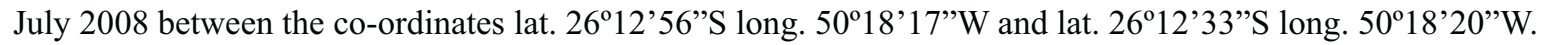
The individual was photographed for the first time on July 3 at 7:30am and for the second time on July 19 at 7:48am for the same place, on the access road to Flona.

Key words: Chrysocyon brachyurus, Flona, lobo-guará, view

\section{Introdução}

O Lobo-guará é o maior representante da família dos canídeos na América do Sul os indivíduos adultos são territorialistas distingue-se dos outros canídeos por sua altura de até $130 \mathrm{~cm}$ e sua pelagem vermelho ouro (Ramos Jr. et al., 2003). São facultativamente monogâmicos por toda a vida com pares se juntando durante a estação de reprodução (abril - julho) para copular, observações de lobos em cativeiro indicam que os machos desempenham papel na criação dos filhotes (Rasmussem e Tilson,1984 apud Fletchall et al., 1995).

A espécie esta classificada como vulnerável no livro vermelho da Fauna Brasileira Ameaçada de Extinção (Machado et al., 2008) e como quase ameaçada pela IUCN (2008).

Uma das principais ameaça a esta espécie e a constante perda do hábitat. Esse processo de redução e isolamento da vegetação natural acaba modificando a estrutura e os processos na paisagem, podendo gerar extinções locais e alterar a composição e a abundância de certas espécies, tanto vegetais quanto animais e, consequentemente, perda de biodiversidade (MMA, 2003). Vários são os fatores que levam o C. brachyurus ao risco de uma extinção estocástica. Apesar de serem animais com hábitos onívoros, eles percorrem grandes extensões à procura de alimento, podendo às vezes deslocar-se por até $15 \mathrm{~km}$ em linha reta. Eles precisam para a reprodução e sobrevivência, grandes áreas, entre 50 a $115 \mathrm{~km}^{2}$ (Carvalho e Vasconcellos, 1995; Silveira, 1999). Sendo assim, uma das principais ameaças à conservação do lobo-guará tem sido a destruição e fragmentação de seu hábitat natural concomitante à intensa ocupação humana, nos segmentos da agricultura, pecuária e turismo desordenados (Rodrigues, 2002). Outra situação-problema para os lobos-guarás em consequência à fragmentação de seus hábitats naturais tem sido a deterioração genética das populações que pode afetar drasticamente o sucesso evolutivo e levar a população à extinção (Lion, 2007).

As interações entre lobos-guarás e seres humanos, ou até mesmo com animais domésticos, também se constitui de grande risco para as populações remanescentes de $C$. brachyurus, que possuem alta sensibilidade a patógenos adquiridos destes animais, tais como, cinomose, adenovirose e raiva (Fletchall, 1995). O mais agravante é que o contágio por esses patógenos pode acontecer não só por meio das interações sociais destes indivíduos, mas também pela simples utilização da mesma área ou dos mesmos recursos naturais (Rodden et al., 2004).

A espécie também está sujeita à pressão de caça. Existem muitos mitos, voltados a esses animais, onde são caçados para transformar partes do seu copo em amuletos, ou curar doenças, em algumas regiões acredita-se em uma lenda, onde é considerado um lobisomem (Ramos Jr. et al., 2003).

O lobo-guará eventualmente preda animais domésticos, especialmente galinhas (Dietz, 1984; Santos, 1999), o que o torna sujeito à pressão de caça. Outro fator de mortalidade importante são os atropelamentos em rodovias, cujas principais vitimas são os canídeos (Vieira, 1996).

No Brasil são encontrados em toda a região compreendida pelo Planalto Central, Pantanal matogrossense, sul da Bacia Amazônica, chegando até áreas de Mata Atlântica dos estados da Bahia, Minas Gerais e São Paulo. Ocorrem em regiões do sul da Bolívia, Paraguai e Argentina (Reis et al., 2006).

No mesmo ano que Cimardi (1996) publica em seu livro que o lobo-guará estaria extinto para o estado de Santa Catarina, os pesquisadores Cherem e Perez (1996) após realizarem um levantamento faunístico das reservas extrativistas da empresa de celulose, papel e embalagens 
RIGESA e arredores no município de Três Barras, SC no Planalto Norte de Santa Catarina registraram, através de entrevista, a presença de um casal de guarás na Flona de Três Barras, SC.

Wallauer et al. (2000), após realizarem um levantamento faunístico na Flona de Três Barras - SC, comparam seus resultados com os inventários faunísticos realizados pela FUPEF (1990) e por Cherem e Perez (1996) realizados na mesma área e não confirmaram a espécie para a área e nem para a região.

O lobo-guará foi incluído por Cherem et al. (2004) na lista das espécies de mamíferos de ocorrência confirmada para Santa Catarina, tomando-se por base exemplares depositados em coleções ou referências bibliográficas.

Este trabalho teve como objetivo relatar a presença, através de visualização do lobo-guará na Floresta Nacional (Flona) de Três Barras, SC.

\section{Material e Métodos}

\section{Área de estudo}

A Floresta Nacional (Flona) de Três Barras - SC localizada entre as latitudes $26^{\circ} 10^{\prime}$ e $26^{\circ} 15^{\prime} \mathrm{S}$ e as longitudes $50^{\circ} 10^{\prime}$ e $50^{\circ} 15^{\prime} \mathrm{W}$ é administrada pelo IBAMA e está localizada no município de Três Barras, na região do Planalto Norte Catarinense, distante aproximadamente $180 \mathrm{~km}$ de Curitiba, PR, $5 \mathrm{~km}$ a leste da cidade de Canoinhas, e a $12 \mathrm{~km}$ sudoeste da cidade de Três Barras, e possui uma área de 4.458,50ha (Figura 1).

A Flona de Três Barras está inserida em uma região de histórica exploração predatória da floresta, pois no início do século passado, a cerca de $15 \mathrm{~km}$ da sede da Flona de Três Barras foi instalada a serraria da "Souther Brazil Lumber \& Colonization Company" (Thomé, 1981; IBAMA, 2003; Marques, 2007).

A exploração madeireira pela "Lumber" durou até 1940, sendo que em 1945 iniciou-se o reflorestamento de araucária, onde esses plantios foram concentrados em áreas altas com o último talhão plantado em 1957. A partir de 1963, o governo federal incentivou as pesquisas e o reflorestamento com Pinus, sendo iniciados os plantios desta espécie nas áreas mais baixas, chegando a atingir 30\% da área total da Flona (FUPEF, 1990; IBAMA, 2003; Marques, 2007). A Flona faz parte do Bioma da "Mata Atlântica", mais especificamente é composta pela "Floresta Ombrófila Mista" (Floresta com Araucária). O relevo da Flona é predominantemente plano a suave-ondulado.

Praticamente todos os limites da Flona são constituídos por rios de acordo com Marques (2007).

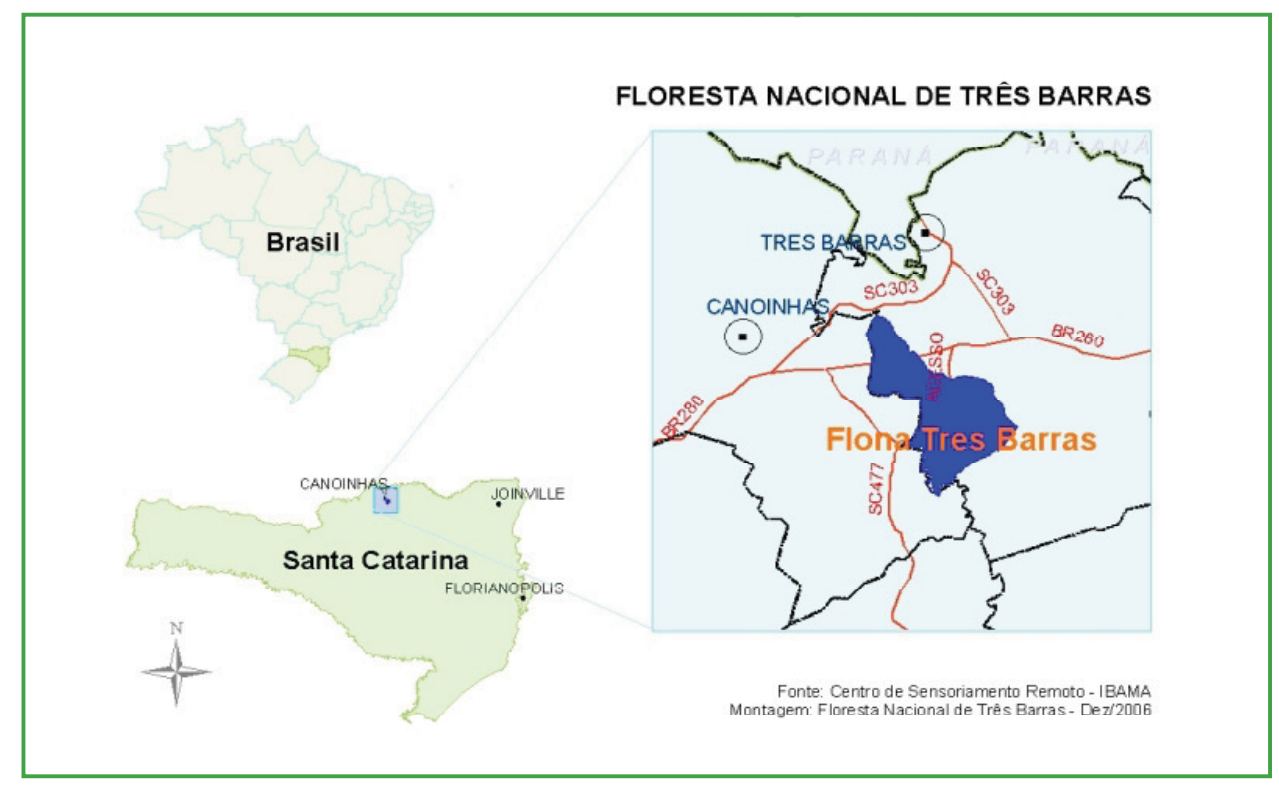

FIGURA 1: Localização da Floresta Nacional de Três Barras, SC. Fonte: Marques (2007). 
Toda a parte oeste é circundada pelo Rio Canoinhas, e Sul pelo Rio Jangada (este rio é denominado como "Baronesa" em alguns mapas e documentos), a leste pelo rio dos Pardos e a ponta Norte pelos rios Canoinhas e Pardos (Marques, 2007).

$\mathrm{O}$ rio Jangadinha tem todas as suas nascentes dentro dos limites da Flona e o mesmo deságua no rio Canoinhas também dentro destes limites. A área é formada por $29,77 \%$ de reflorestamento de Pinus sp., além de vegetação arbórea nativa como florestas com araucária. As matas ciliares e as de reflorestamento com araucária, perfazem $45,69 \%$ do território da Flona, totalizando uma importante área de proteção à fauna e flora (Marques, 2007). As áreas com várzeas somam $18,56 \%$ e são formadas basicamente por gramíneas e ciperáceas que constituem uma proteção importante a este ecossistema que vem sendo sistematicamente destruído em toda a região. Marques (2007) ressalta, ainda, que a Flona faz divisa com Áreas do Exército que somando totalizam-se mais de 14 mil hectares com relativa proteção.

O clima da Flona é típico do Planalto Norte Catarinense que, de acordo com a EPAGRI (2001), é classificado como Cfb, segundo Köeppen, ou seja, clima temperado constantemente úmido, sem estação seca, com verão fresco e inverno com geadas frequentes. Sua precipitação média anual é de $1.588,5 \mathrm{~mm}$ bem distribuídos ao longo do ano, sendo abril o mês mais seco $(90,1 \mathrm{~mm})$ e outubro o mais chuvoso $(197,5 \mathrm{~mm})$. A temperatura média do mês mais frio é de $11,7^{\circ} \mathrm{C}$ em julho e do mês mais quente é de $21,3{ }^{\circ} \mathrm{C}$ em janeiro (Marques, 2007).

Para a obtenção do registro visual do animal foi utilizada uma máquina digital da marca Sony e as coordenadas do local das visualizações foi obtida através do GPS Garmin etrex.

\section{Resultados e Discussão}

Um exemplar adulto de lobo-guará começou a ser visualizado pelas manhãs por funcionários do Ibama, logo após o período de intensa circulação de pessoas, final de coleta de pinhão na área da Flona, final do mês de junho de 2008. O lobo era visualizado geralmente entre as sete e nove horas pelos funcionários quando estavam chegando para trabalhar, geralmente era visto uma única vez por dia entre as coordenadas (lat. $26^{\circ} 12^{\prime} 56^{\prime \prime} \mathrm{S}$; long. $50^{\circ} 18^{\prime} 17^{\prime \prime} \mathrm{W}$ e lat. $26^{\circ} 12^{\prime} 33^{\prime \prime}$ 's; long. 50 $\left.10^{\circ} 20^{\prime \prime} \mathrm{W}\right)$. Ele foi fotografado pela primeira vez em três de julho às $7 \mathrm{~h} 30$ min e a segunda vez no dia 19 do mesmo mês às $7 \mathrm{~h} 48 \mathrm{~min}$. As visualizações e fotografias foram no mesmo local, na estrada de acesso à sede da Flona.

Durante as visualizações o exemplar percorria a estrada que dá acesso à sede da Flona e apresentava um comportamento típico de forrageio, como descrito por Nowak (1991). O espécime percorria lentamente a estrada, parava, escutava, saía da estrada, dava pequenos saltos nas gramíneas, retornava para a estrada, percorria mais um trecho e repetia o comportamento. Quando percebia nossa presença fugia geralmente para a floresta.

O registro visual da espécie é de suma importância, pois corrobora 13 anos após o registro da espécie por entrevista por Cherem e Perez (1996) a presença da espécie para a área.

A área da Flona e do exército possuem aproximadamente 14 mil hectares $\left(140 \mathrm{~km}^{2}\right)$ e como apresentam certa proteção quanto à caça, fogo e desmatamento, é provável que mais espécimes possam estar presentes na área, já que o lobo-guará pode apresentar território entre 30 a $57 \mathrm{~km}^{2}$ (Dietz,1984; Rodrigues, 2002).

São necessários projetos pesquisa para avaliar quais os principais problemas que esta espécie enfrenta na região e determinar qual o tamanho da sua população.

O lobo-guará pode ser considerado uma espécie guarda-chuva para a área da Flona de Três Barras, SC.

\section{Agradecimentos}

Ao Instituto Brasileiro do Meio Ambiente e dos Recursos Naturais Renováveis (IBAMA) por disponibilizar a área da Flona para esta pesquisa, em especial aos funcionários da Flona pelas informações, ao Anésio da Cunha Marques, pelas fotos, ao Artur e Carlos pelo apoio e incentivo. 


\section{Referências}

Carvalho, C. T. E.; Vasconcellos, L. E. M. 1995. Disease, food and reproduction of the maned wolf - Chrysocyon brachyurus (Illiger) (Carnivora, Canidae) in southeast Brazil. Revista Brasileira de Zoologia, 12 (3): 627-640.

Cherem, J. J.; Perez, D. M. 1996. Mamíferos terrestres de Floresta de Araucária no Município de Três Barras - SC. Biotemas, 9 (2): 29-46.

Cherem, J. J.; Simões-Lopes, P. C.; Althoff, S.; Graipel, M. E. 2004. Lista dos mamíferos do estado de Santa Catarina, Sul do Brasil. Mastozoología Neotropical, 11 (2): 151-184.

Cimardi, A. V. 1996. Mamíferos de Santa Catarina. Fundação de Amparo à Tecnologia e Meio Ambiente, Florianópolis, Brasil, 302pp.

Dietz, J. M. 1984. Ecology and social organization of the maned wolf. Smithsonian Contributions to Zoology, 392: 1-51.

EPAGRI, 2001. Dados e informações biofísicas da Unidade de Planejamento Regional Planalto Norte Catarinense - UPR 4. Ed. EPAGRI, Florianópolis, Brasil, 81pp.

Fletchall, B. N.; Rodden, M.; Taylor, S. 1995. Manual de manejo do lobo-guará. CEPREM, São Paulo, Brasil, 87pp.

FUPEF. 1990. Aspectos faunísticos da Floresta Nacional de Três Barras, SC. Fundação de Pesquisas Florestais do Paraná. Curitiba, Brasil, 26pp.

IBAMA, 2003. Floresta Nacional de Três Barras - Informações gerais. IBAMA, Três Barras, Brasil, 30pp.

IUCN. 2008. Red list of threatened species. Disponível em <http:// www.iucnredlist.org $>$. Acesso em 10 de janeiro de 2009.

Lambeck, R. J. 1997. Focal species: A multi-species umbrella for nature conservation. Conservation Biology, 11: 849-856.

Lion, M. B. 2007. Diversidade genética e conservação do loboguará, Chrysocyon brachyurus, em áreas protegidas do Distrito Federal. Dissertação de Mestrado, Universidade de Brasília, Brasil, 66pp.

Machado, A. B. M.; Drummond, G. M.; Paglia, A. P. 2008. Livro vermelho da fauna brasileira ameaçada de extinção. $2^{a}$ ed. MMA e Fundação Biodiversitas, Brasília e Belo Horizonte, Brasil, $1420 \mathrm{pp}$.
Marques, C. A. 2007. Planejamento da paisagem da Floresta Nacional de Três Barras (Três Barras - SC): Subsídios ao plano de manejo. Dissertação de Mestrado, Universidade Federal do Paraná, Brasil, 145pp.

MMA. 2003. Fragmentação de ecossistemas: Causas, efeitos sobre a biodiversidade e recomendações de políticas públicas. Ministério do Meio Ambiente, Brasília, Brasil, 510pp.

Nowak, R.M. 1991. Walker's mammals of the world. v.II. The Johns Hopkins University Press, Baltimore and London, USA and UK, 1629pp.

Ramos Jr., V. A.; Pessutti, C.; Chieregatto, C. A. F. S. 2003. Guia de identificação dos canídeos silvestres brasileiros. Joyloy Studio Ltda, Sorocaba, Brasil, 35pp (formato digital).

Reis, N. R.; Peracchi, A. L.; Pedro, W. A.; Lima, I. P. 2006. Mamíferos do Brasil. UEL, Londrina, Brasil, 437pp.

Rodden, M.; Rodrigues, F.; Bestelmeyer, S. V. 2004. Maned wolf (Chrysocyon brachyurus). In: Sillero-Zubiri, C.; Hoffmann, M. \& MacDonald, D. W. (Eds). Canids: Foxes, wolves, jackals and dogs. Status survey and conservation action plan. IUCN/SSC, Canid Specialist Group, Gland and Cambridge, Switzerland and UK, p.38-44.

Rodrigues, F. H. G. 2002. Biologia e conservação do lobo-guará na Estação Ecológica de Águas Emendadas, DF. Tese de Doutorado em Ecologia. Universidade Estadual de Campinas, Brasil, 105pp.

Santos, E. F. 1999. Ecologia alimentar e dispersão de sementes pelo lobo-guará (Chrysocyon brachyurus) em uma área rural no sudeste do Brasil (Carnivora: Canidae). Dissertação de Mestrado, Universidade Estadual Paulista, Brasil, 68pp.

Silveira, L. 1999. Ecologia e conservação dos mamíferos carnívoros do Parque Nacional das Emas, Goiás. Dissertação de Mestrado, Universidade Federal de Goiás, Brasil, 177pp.

Thomé, N. 1981. Civilizações primitivas do Contestado. Imprensa Universal, Caçador, Brasil, 80pp.

Vieira, E. M. 1996. Highway mortality of mammals in Central Brazil. Ciência Cultura, 48 (4): 270-272.

Wallauer, J. P. 2000. Levantamento dos mamíferos da Floresta Nacional de Três Barras, SC. Biotemas, 13 (1): 103-127. 